\title{
Kajian Penyusunan Peta Proses Bisnis pada Pembangunan Desa di Kabupaten Subang
}

\author{
Khansa Shabiyhah NK*, Ernady Syaodih
}

Prodi Teknik Perencanaan Wilayah \& Kota, Fakultas Teknik, Universitas Islam Bandung, Indonesia.

*khansashabiyhah@gmail.com, ernadysyaodih@gmail.com

\begin{abstract}
Business Process is a collection of interrelated work to solve a particular problem. Village development cannot be separated from the context of regional management both at the district and provincial levels because the position of the village in a wider context (social, economic, market access, and politics) must look at the interrelationships between villages and others. Therefore, it is necessary to have a business process map. Compilation of Business Process Map in accordance with Permenpan N0.19 of 2018 concerning Compilation of Business Process Map of Government Agencies. Problems faced What problems are faced in village development in Subang Regency?, who is involved in the village development process in Subang Regency?, what are the duties, functions and coordination of each stakeholder?. and what is the shape of the business process map in village development so that it runs efficiently and effectively? With the study of business process maps, it can increase knowledge assets that can integrate and document in detail the business processes carried out to achieve the vision, mission, and goals. This knowledge asset forms the basis for decision making regarding organizational development and human resources, as well as performance appraisal. The conclusion is that the business process map in village development still has problems in every flow of activities
\end{abstract}

Keywords: business process, village development.

Abstrak. Bisnis Proses adalah suatu kumpulan pekerjaan yang saling terkait untuk menyelesaikan suatu masalah tertentu. Pembangunan desa tidak terlepas dari konteks manajemen pembangunan daerah baik di tingkat kabupaten maupun tingkat provinsi karena kedudukan desa dalam konteks yang lebih luas (sosial, ekonomi, akses pasar, dan ploitik) harus melihat keterkaitan antar desa dan dengan yang lainnya. Oleh karena itu perlu di adakannya peta proses bisnis. Penyusunan Peta Proses Bisnis sesuai Permenpan N0.19 tahaun 2018 tentang Penyusunan Peta Proses Bisnis Instansi Pemerintah. Adapun permasalahan yang dihadapai Permasalahan apa saja yang dihadapi dalam pembangunan desa di Kabupaten Subang?, siapa saja yang terlibat dalam proses pembangunan desa di Kabupaten Subang?, bagaimana tugas, fungsi dan koordinasi dari setiap pemangku kepentingan?. dan bagaimana bentuk peta proses bisnis dalam pembangunan desa agar berjalan efisien dan efektif ?. Dengan adanya kajian peta proses bisnis maka dapat meningkatkan aset pengetahuan yang dapat mengintegrasikan dan mendokumentasikan secara rinci mengenai proses bisnis yang dilakukan untuk mencapai visi, misi, dan tujuan. Aset pengetahuan ini menjadi dasar pengambilan keputusan strategis terkait pengembangan organisasi dan sumber daya manusia, serta penilaian kinerja. Kesimpulannya bahwa peta proses bisnis pada pembangunan desa masih memiliki masalah pada setiap alur kegiatannya.

Kata Kunci: proses bisnis, pembangunan desa. 


\section{A. Pendahuluan}

Pembangunan desa di Kabupaten Subang masih belum merata sehingga masih ada desa yang tertinggal dari konsep yang ideal. Faktor-faktor yang mempengaruhi, Identifikasi permasalahan tersebut antara lain: (i) Persentase Aparatur yang mengikuti pelatihan : kapasitas aparatur pemerintah desa masih rendah, masih rendah kinerja kelembagaan pemerintah desa, belum tertibnya administrasi desa, masih banyaknya desa yang belum memanfaatkan potensi secara optimal, perlu adanya pengkajian terhadap tingkat perkembangan desa (klasifikasi desa hampir seluruhnya pada kondisi pola minimal); (ii) Persentase Penetapan RPJMDes : banyak Pemerintah Desa masih belum mempunyai rencana kerja yang tertuang dalam RPJMDes ,Rencana Program Jangka menengah Desa artinya Pemerintah Desa harus punya program terukur dalam menjalankan pemerintahannya; (iii) Presentase Desa yang menggunakan profil berbasis Online : masih adanya kantor desa yang sarana prasarananya kurang baik(belum tertatanya kualitas IT yang memadai untuk menunjang program siskeudes dan profile desa online, pelayanan administrasi terpadu); (iv) Persentase pengelolaan keuangan desa melalui aplikasi siskeudes : masih adanya kantor desa yang sarana prasarananya kurang baik(belum tertatanya kualitas IT yang memadai untuk menunjang program siskeudes dan profile desa online, pelayanan administrasi terpadu); (v) Jumlah BUMDes JAWARA : pengelolaan dan pembentukan BUMDes Jawara masih belum maksimal, ini mengakibatkan perekonomian Desa lambat berkembang; (vi) Persentase kelompok binaan lembaga pemberdayaan masyarakat (LPM) : kelembagaan masyarakat dalam kinerjanya masih belum optimal, belum bersinerginya antar kelembagaan yg ada di perdesaan serta masih rendahnya kapasitas kader pembangunan dan anggota kelembagaan masyarakat; (vii) Presentase swadaya masyarakat dalam pelaksanaan program pembangunan melalui lembaga pemberdayaan masyarakat (LPM) : kurangnya peran serta swadya masyarakat terhadap program pemerdayaan masyarakat, lembaga-lembaga swadaya masyarakat belum mengerti arti petingnya pemberdayaan masyarakat; (viii) Nilai Evaluasi AKIP : laporan Akuntabilas Kinerja Instansi Pemerintah yang merupakan gambaran dari baik buruknya suatu kinerja pemerintah, di harapkan setiap tahunnya ada peningkatan baik; (ix) Indeks Kepuasan Masyarakat : Survey Indeks Kepuasan Masyarakat adalah suatu hasil survey baik buruknya suatu pelayanan Instansi Pemerintah, terhadap suatu pelayanan terhadap masyarakat, yang diharapkan setiap tahunnya ada peningkatakan yang baik terhadap pelayanan. (Sumber: RENSTRA Dinas Pmberdayaan Desa 2018-2023 Kabupaten Subang)

Contohnya Desa Cibuluh Kecamatan Tanjungsiang, desa ini memiliki potensi sebagai desa wisata, desa wisata merupakan jenis wisata yang menerapkan konsep wisata pedesaan yang beriringan dengan alam. Untuk dapat melihat alur pembangunan desa yang terstruktur maka perlu di adakannya peta proses bisnis agar dapat melihat kagiatan dari pembangunan suatu desa, sehingga terdapat gambaran yang jelas. Tetapi dalam hal pembuatan peta proses bisnis masih banyak pihak yang belum mengerti tentang langkah-langkah apa saja yang pelu dilakukan dalam pembangunan desa yang dimasukan kedalam peta proses bisnis.

Berdasarkan latar belakang yang telah diuraikan, maka perumusan masalah dalam penelitian ini sebagai berikut:

1. Permasalahan apa saja yang dihadapi dalam pembangunan desa di Kabupaten Subang ?;

2. siapa saja yang terlibat dalam proses pembangunan desa di Kabupaten Subang ?;

3. bagaimana tugas, fungsi dan koordinasi dari setiap pemangku kepentingan ?; dan

4. bagaimana bentuk peta proses bisnis dalam pembangunan desa agar berjalan efisien dan efektif ?.

5. Selanjutnya, tujuan dalam penelitian ini diuraikan dalam pokok-pokok sbb.

6. Untuk mengetahui permasalahan pembangunan desa yang berbasis pada peta proses bisnis;

7. untuk mengetahui siapa saja pihak yang terlibat dalam pembanguan desa dalam peta proses bisnis;

8. untuk mengetahui apa saja tugas dari setiap pemangku kepentingan dalam pembangunan desa; dan

9. untuk megetahui bentuk peta proses bisnis pada pembangunan desa. 


\section{B. Metodologi Penelitian}

Metode analisis menggunkan Peraturan Menteri Pendayagunaan Aparatur Negara Dan Reformasi Birokrasi Republik Indonesia Nomor 19 Tahun 2018 dan PDCA (Plan, DO, Check, dan Act). Penyusunan peta proses bisnis dilakukan melalui 4 (empat) tahapan, yaitu : Tahap Persiapan dan Perencanaan, Tahap Pengembangan, Penyusunan peta proses bisnis menggunakan level atau tingkatan, dan Penyusunan peta proses bisnis menggunakan jenis gambar peta.

\section{Hasil Penelitian dan Pembahasan}

Permasalahan apa saja yang dihadapi dalam pembangunan desa di Kabupaten Subang

Berikut adalah penelitian mengenai permasalahan yang dihadapi dalam pembangunan desa di Kabupaten Subang:

Tabel 1. Kendala Stakeholder Pada Peta Proses Bisnis

\begin{tabular}{|c|c|c|}
\hline No & Stakeholder & Kendala \\
\hline \multirow{5}{*}{1} & \multirow{5}{*}{$\begin{array}{l}\text { Dinas Pemberdayaan } \\
\text { Desa }\end{array}$} & Masyarakat masih kurang mehamami tentang BUMDES \\
\hline & & $\begin{array}{l}\text { Perlu adanya struktur desa dan fungsi dari jabatan desa yang } \\
\text { lebih jelas }\end{array}$ \\
\hline & & $\begin{array}{l}\text { Kurang terorganisir kelembagaan dan pengembangan } \\
\text { partisipasi masyarakat }\end{array}$ \\
\hline & & Masyarakat masih kurang memahami tentang usaha ekonomi. \\
\hline & & Kurang berkoordinasi antara pihak satu dengan yang lainnya. \\
\hline \multirow{6}{*}{2} & \multirow{6}{*}{ PUPR } & $\begin{array}{l}\text { Masih adanya beberapa tempat yang tidak sesuai dengan } \\
\text { peruntukannya. Seperti sawah dialih fungsikan menjadi } \\
\text { rumah. }\end{array}$ \\
\hline & & $\begin{array}{l}\text { Kurangnya partisipasi untuk memanfaatkan ruang yang } \\
\text { sudah tersedia. }\end{array}$ \\
\hline & & Infrastruktur yang masih belum merata. \\
\hline & & Kurang optimalnya pengelolaan sumber daya air. \\
\hline & & $\begin{array}{l}\text { Kurangnya antusiasnya masyarakat untuk pemeliharaan } \\
\text { seperi : bangunan gedung yang sudah pemerintah sediakan. }\end{array}$ \\
\hline & & Masih belum tersosialisasi tentang PAMSIMAS. \\
\hline \multirow{2}{*}{3} & \multirow{2}{*}{ DPKP } & Belum meratanya permukman yang layak \\
\hline & & Belum meratanya perumahan yang layak \\
\hline \multirow{3}{*}{4} & \multirow{3}{*}{ DISHUB } & Tidak adanya rambu-rambu lalulintas di desa. \\
\hline & & $\begin{array}{l}\text { Masih kurangnya sarana perhubungan yang dapat } \\
\text { menghubungkan desa dengan kota. }\end{array}$ \\
\hline & & Tidak adanya angkutan umum yang menuju ke desa. \\
\hline 5 & $\begin{array}{l}\text { Kecamatan } \\
\text { (Tanjungsiang) }\end{array}$ & Kurangnnya anggaran untuk pembangunan desa. \\
\hline 6 & Desa Wisata CIbuluh & Kurangnnya anggaran untuk pembangunan desa. \\
\hline \multirow[t]{2}{*}{7} & \multirow[t]{2}{*}{ Dinas Pariwisata } & $\begin{array}{l}\text { Kurang dikembangkannya destinasi wisata di desa tersebut, } \\
\text { sehingga masyarakat masih kurang antusias terhadap } \\
\text { desanya. }\end{array}$ \\
\hline & & Kurang promosi terhadap masyarakat sekitar. \\
\hline 8 & Perguruan Tinggi & Kurang berperan aktif dalam mewujudkan desa wisata. \\
\hline 9 & BUMDES & Masyarakat masih kurang mehamami tentang BUMDES. \\
\hline 10 & $\begin{array}{l}\text { Badan } \\
\text { Permusyawaratan Desa }\end{array}$ & Kurang anggaran, kurangnya tempat serta terbatasnya SDM. \\
\hline 11 & Karangtaruna & $\begin{array}{l}\text { Karangtaruna didesa } \\
\text { pembangunan desa. }\end{array}$ \\
\hline
\end{tabular}




\begin{tabular}{|l|l|l|}
\hline No & \multicolumn{1}{|c|}{ Stakeholder } & \multicolumn{1}{c|}{ Kendala } \\
\hline 12 & Petani & Kurang memahami alur dari pembangunan desa wisata. \\
\hline 13 & Pegiat Pariwisata & Kurang memahami alur dari pembangunan desa wisata. \\
\hline 14 & Pelaku Agribisnis & Kurang memahami alur dari pembangunan desa wisata. \\
\hline 15 & Pelaku Agroindustri & Kurang memahami alur dari pembangunan desa wisata. \\
\hline 16 & $\begin{array}{l}\text { Pelaku Industri } \\
\text { Cindramata }\end{array}$ & $\begin{array}{l}\text { Kurangnya toko-toko untuk berjualan cindramata, sehingga } \\
\text { wisatawan yang datang tidak dapat memilih cindramata secra } \\
\text { bebas. }\end{array}$ \\
\hline 17 & $\begin{array}{l}\text { Pelaku Promosi } \\
\text { Pariwisata }\end{array}$ & Kurangnya promosi wisata untuk desa. \\
\hline \multirow{2}{*}{18} & DISKOMINFO & $\begin{array}{l}\text { Minimnya jaringan didesa, sehingga agak sulit untuk } \\
\text { mengakses internet, dan menemukan lokasi wisata. }\end{array}$ \\
\cline { 3 - 3 } & Belum merata berkembangnya teknologi didesa. \\
\hline
\end{tabular}

Sumber: Hasil Analisis Penulis, 2021

\section{Siapa saja yang terlibat dalam proses pembangunan desa di Kabupaten Subang}

Yang terlibat dalam pembangunan Desa Wisata Cibuluh adlah: BP4D, BKAD, Kepala Dinas DISPEMDES, DISPEMDES Bid. Pengelolaan Keuangan dan Aset Desa, DISPEMDES Bid. Kelembagaan dan Pengembangan Partisipasi Masyarakat, DISPEMBED Bid.PUEM, DISPEMDES Bid.Pemerintahan Desa, Kecamatan (Tanjungsiang), Desa Wisata Cibuluh, PUPR, DPKP, DISHUB, Dinas Pariwisata, DISKOMINFO, Pelaku Promosi Pariwisata, Perguruan Tinggi, BUMDES, BPD, Karangtaruna, Pegiat Pariwisata, Petani, Pelaku Agribisnis/Tengkulak, Pelaku Agroindustri, dan Pelaku Industri Cinderamata.

\section{Bagaimana tugas, fungsi dan koordinasi dari setiap pemangku kepentingan}

Tabel 2. Stakeholder Dalam Pembanguanan Desa

\begin{tabular}{|c|c|c|}
\hline No & Stakeholder & Peran \\
\hline 1 & $\begin{array}{l}\text { Dinas Pemberdayaan } \\
\text { Desa }\end{array}$ & $\begin{array}{l}\text { Peran Dinas Pemberdayaan Masyarakat dan Desa Kabupaten } \\
\text { Subang yaitu sebagai pemecah masalah dan sebagai fasilitator, } \\
\text { menyelenggarakan Perumusan dan Pelaksanaan Teknis } \\
\text { kebijakan pemerintahan Desa, Kelembagaan dan Pengembangan } \\
\text { Partisipasi Masyarakat, usaha ekonomi masyarakat, dan } \\
\text { Pengelolaan Keuangan dan Aset Desa. }\end{array}$ \\
\hline 2 & PUPR & $\begin{array}{l}\text { Pembangunan infrastruktur desa dan pengawasan kebijakan } \\
\text { teknis serta penyelenggaraan dalam melaksanakan kegiatan } \\
\text { pembangunan, serta pengendalian operasional jalan, jembatan } \\
\text { dan bangunan pelengkap. Pembangunan sumber daya alam dan } \\
\text { lingkungan hidup memiliki kegiatan berbagai sektor } \\
\text { pembangunan agar tercipta keseimbangan dan kelestarian fungsi } \\
\text { sumber daya alam dan lingkungan hidup sehingga keberlanjutan } \\
\text { pembangunan tetap terjamin. }\end{array}$ \\
\hline 3 & DPKP & $\begin{array}{l}\text { Menyelenggarakan, pengkajian bahan kebijakan teknis serta } \\
\text { regulasi dan perencanaan fasilitasi pembangunan, } \\
\text { pengembangan serta inventarisasi perumahan perkotaan dan } \\
\text { perumahan perdesaan serta kegiatan monitoring, pembinaan dan } \\
\text { penyuluhan, serta penyelenggaraan pengaturan, pembinaan, } \\
\text { pembangunan dan pengendaliaan terhadap pelaksanaan } \\
\text { perumahan perkotaan, perumahan perdesaan dan } \\
\text { pengembangan kawasan }\end{array}$ \\
\hline 4 & DISHUB & $\begin{array}{l}\text { Peranan dalam pembangunan perdesaan yaitu : tentang adanya } \\
\text { rute transportasi dari desa menuju kota. Melaksanakan }\end{array}$ \\
\hline
\end{tabular}




\begin{tabular}{|c|c|c|}
\hline No & Stakeholder & Peran \\
\hline & & $\begin{array}{l}\text { pembinaan dan pengelolaan sarana dan prasarana keterminalan, } \\
\text { perpakiran dan lalu lintas. }\end{array}$ \\
\hline 5 & $\begin{array}{l}\text { Kecamatan } \\
\text { (Tanjungsiang) }\end{array}$ & $\begin{array}{l}\text { peranan kecamatan merupakan salah satu lembaga supra desa, } \\
\text { yang mana salah satu tugasnya adalah melakukan pembinaan } \\
\text { dan pengawasan terhadap pemerintahan desa/kelurahan dalam } \\
\text { rangka tertib. }\end{array}$ \\
\hline 6 & Desa Wisata Cibuluh & $\begin{array}{l}\text { peranan yang seperti pengarahan kepada masyarakat untuk } \\
\text { berpartisipasi dalam pembangunan dan penyaluran aspirasi } \\
\text { masyarakat. }\end{array}$ \\
\hline 7 & Dinas Pariwisata & $\begin{array}{l}\text { Mengembangkan potensi obyek wisata sebagai koordinator, dan } \\
\text { penyelenggaraan pengembangan strategi pemasaran pariwisata. }\end{array}$ \\
\hline 8 & Perguruan Tinggi & $\begin{array}{l}\text { Peran perguruan tinggi berkontribusi dalam membangun desa } \\
\text { wisata. }\end{array}$ \\
\hline 9 & BUMDES & $\begin{array}{l}\text { BUMDES bertujuan meningkatkan perekonomian desa, } \\
\text { mengoptimalkan aset desa agar bermanfaat untuk kesejahteraan } \\
\text { masyarakat desa, meningkatkan usaha masyarakat dalam } \\
\text { pengelolaan potensi ekonomi desa. }\end{array}$ \\
\hline 10 & $\begin{array}{l}\text { Badan } \\
\text { Permusyawaratan } \\
\text { Desa }\end{array}$ & $\begin{array}{l}\text { BPD mempunyai fungsi, membahas menampung dan } \\
\text { menyalurkan aspirasi dari warga desa pada Kepala desa yang } \\
\text { kemudian dijadikan pedoman oleh Kepala Desa beserta } \\
\text { jajarannya dalam melaksanakan program pembangunan } \\
\text { desanya. }\end{array}$ \\
\hline 11 & Karangtaruna & $\begin{array}{l}\text { Perannya memiliki strategi marketing dengan melakukan } \\
\text { promosi baik dari media sosial maupun promosi antar suara, } \\
\text { melaksanakan kegiatan sebagai pemandu wisatawan yang } \\
\text { berkunjung. }\end{array}$ \\
\hline 12 & Petani & $\begin{array}{l}\text { peranan petani dalam pembangnan Desa wisata Cibuluh yaitu } \\
\text { memanfaatkan potensi pertanian sebagai objek wisata. }\end{array}$ \\
\hline 13 & Pegiat Pariwisata & $\begin{array}{l}\text { Pegiat paiwisata memiliki peran yaitu dapat membangkitkan } \\
\text { semangat masyarakat setempat dalam membanngun desa wisata. }\end{array}$ \\
\hline 14 & Pelaku Agribisnis & $\begin{array}{l}\text { Desa wisata Cibuluh pertanian termasuk kedalam wisata oleh } \\
\text { karena itu wisatawan dapat belajar untuk pertanian. }\end{array}$ \\
\hline 15 & Pelaku Agroindustri & $\begin{array}{l}\text { Agroindustri meliputi industri pengolahan hasil pertanian, } \\
\text { industri yang memproduksi peralatan dan mesin pertanian, } \\
\text { industri input pertanian (pupuk, pestisida, herbisida dan lain- } \\
\text { lain) dan industri jasa sektor pertanian. }\end{array}$ \\
\hline 16 & $\begin{array}{l}\text { Pelaku Industri } \\
\text { Cindramata }\end{array}$ & $\begin{array}{l}\text { memiliki peran pembangunan desa wisata, karena dengan } \\
\text { adanya industry cindramata para wisatawan yang datang dapat } \\
\text { membeli oleh-oleh/ciri khas Desa wisata Cibuluh untuk dibawa } \\
\text { ke daerah asalnya. }\end{array}$ \\
\hline 17 & $\begin{array}{ll}\text { Pelaku } & \text { Promosi } \\
\text { Pariwisata } & \end{array}$ & $\begin{array}{l}\text { mempromosikan desa wisata agar diketahui oleh masyarakat } \\
\text { banyak, sehingga dapat menarik wisatawan untuk datang ke } \\
\text { Desa wisata Cibuluh, }\end{array}$ \\
\hline 18 & DISKOMINFO & Peranan membagian informasi kepada masyarakat. \\
\hline
\end{tabular}

Sumber: Hasil Analisis Penulis, 2021 
Bagaimana bentuk peta proses bisnis dalam pembangunan desa agar berjalan efisien dan efektif

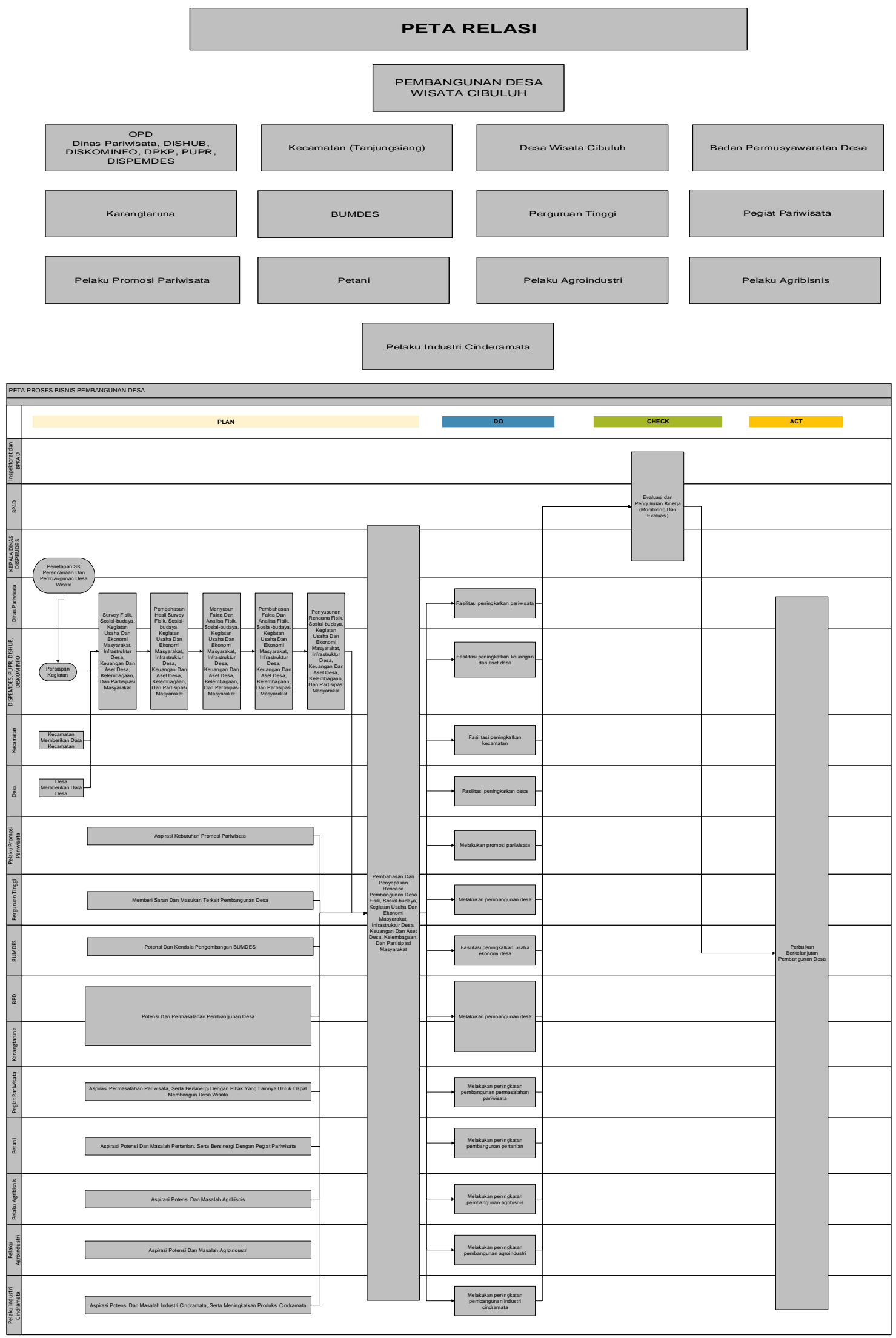




\section{Kesimpulan}

Berdasarkan pembahasan dalam penelitian ini, peneliti menyimpulkan beberapa hasil penelitian sebagai berikut:

1. Tahapan pembangunan desa terdapat 4 tahap: a). Plan (Perencanaan): yang terlibat dalam tahap plan yaitu dinas pemberdayaan desa, PUPR, DPKP, DISHUB, Kecamatan (Tanjungsiang), Desa Wisata Cibuluh, Dinas Pariwisata, Perguruan Tinggi, BUMDES, BPD, karangtaruna, petani, Pegiat pariwisata, Pelaku Agribisnis, Pelaku agroindustry, Pelaku industri cinderamata, Pelaku promosi pariwisata, dan Diskominfo. Stakeholder yang terkait akan membahas tentang pembangunan desa dari awal tahapan persiapan, survey, pembahasan hasil survey, menyusun fakta dan analisis, pembahasan fakta dan analisis, penyusunan, dan tahapan Pembahasan dan penyepakan rencana pembangunan desa, b). Do (Pelaksanaan): dinas pemberdayaan desa, PUPR, DPKP, DISHUB, Kecamatan (Tanjungsiang), Desa Wisata Cibuluh, Dinas Pariwisata, Perguruan Tinggi, BUMDES, BPD, karangtaruna, petani, Pegiat pariwisata, Pelaku Agribisnis, Pelaku agroindustry, Pelaku industri cinderamata, Pelaku promosi pariwisata, dan Diskominfo. Stakeholder yang terkait mempunyai peran untuk keberlanjutan pembangunan desa, c). Check (Evaluasi): yang teribat dalam tahapan ini adalah inspektorat BPKAD (Badan Pengelolaan Keuangan dan Aset Daerah), BP4D, dan kepala dinas DISPEMDES, yaitu mengevaluasi dan Pengukuran Kinerja, dan Act (Perbaikan berkelanjutan): yang teribat dalam tahapan ini adalah semua skateholder, yaitu Perbaikan Berkelanjutan Pembangunan Desa;

2. bottle neck yang terdapat dalam peta proses bisnis pembangunan Desa Wisata Cibuluh terdapat di semua aspek minimal, sehingga perlu perbeikan/peningkatan dari semua aspek agar dapat menjadi peta proses bisnis yang efektif dan efisien.

\section{Acknowledge}

Puji dan syukur kehadirat Allah SWT yang telah memberikan rahmat dan hidayah-Nya kepada penulis, sehingga penulis dapat menyelesaikan Jurnal Tugas Akhir dengan judul "Kajian Penyusunan Peta Proses Bisnis Pada Pembangunan Desa DiKabupaten Subang". Tidak terlepas dari itu, penyusun menyadari bahwa masih terdapat kekurangan dalam penyusunan, baik dari materi atau tata bahasa. Oleh karena itu penyusun kata penulis berharap Jurnal Tugas Akhir ini dapat bermanfaat bagi penulis dan umumnya bagi para akademisi dan pembaca lainnya, baik sebagai bahan literatur maupun sebagai bahan bacaan.

\section{Daftar Pustaka}

[1] Danilova, K. (2018). Process Owners In Business Process Management: A Systematic Literature Revie. Business Process Management Journal. November 2018. Departemen Strategi dan Manajemen, Sekolah Ekonomi Norwegia (NHH), Bergen, Norwegia Page 1463-7154

[2] Dinas Pemberdayaan Masyarakat Kabupaten Subang. 2018. Rencana Strategi Dinas Pemberdayaan Masyarakat 2018-2023.

[3] Ivan Vincek. Proses Bisnis Sebagai Sistem Bisnis. doi.org. Volume 12. 2018. ISSN 18466168

[4] M Ghufran H, Kordi K. 2020. Mencapai Tujuan Pembangunan Berkelanjutan Dari Desa. https://baktinews.bakti.or.id/artikel/mencapai-tujuan-pembangunan-berkelanjutan-daridesa. Diakses pada tanggal 29 November 2020

[5] Peraturan Menteri Pendayagunaan Aparatur Negara Dan Reformasi Birokrasi Republik Indonesia. 2018. No 19 Tahun 2018 tentang Penyusunan Peta Proses Bisnis Instansi Pemerintah.

[6] Purabaya, R., Wayan, W., Bambang, T. (2019). Model Arsitektur Proses Bisnis Badan Usaha Milik Desa dengan Menggunakan Process Classification Framework (Studi Kasus: Badan Usaha Milik Desa "Cahaya Buana Paku Banten", Desa Sukatani, Kecamatan Cikande, Kabupaten Serang). JURNAL INFORMATIK Edisi ke-15. No. 2. 
Agustus 2019. Universitas Pembangunan Nasional Veteran Jakarta. Jakarta. Page 102112

[7] Rahmawati Dwi, Retno Indah Rokhmawati, Andi Reza Perdanakusuma. Analisis dan Pemodelan Proses Bisnis Bidang Pelayanan Perizinan Menggunakan Bussiness Process Model and Notation (BPMN) (Studi Pada Dinas Penanaman Modal dan Pelayanan Terpadu Satu Pintu Pemerintah Kota Malang). Jurnal Pengembangan Teknologi Informasi dan Ilmu Komputer. Vol. 1, No. 11, November 2017. e-ISSN: 2548-964X

[8] Saari Ulla A, Leena Aarikka-Stenroos, dkk. Sustainable Business Model Ideation and Development of Early Ideas for Sustainable Business Models: Analyzing a New Tool Facilitating the Ideation Process. S. J. Mäkinen. Dalam, (https://doi.org/10.1007/978-3319-93275-0_5)

[9] Syaodih, E. (2015). Manajemen Pembangunan Kabupaten dan Kota. Bandung: Refika Aditama.

[10] Tamu Editorial, Mangonfigurasi ulang Proses Bisnis dalam lanskap politik dan teknologi baru, Jurnal Manajemen Proses Bisnis, Volume 25, Nomor 3, 2019, DOI 10.1108 / BPMJ-06-2019-377

[11] Tamu Editorial, Transfer Pengetahuan dan Kinerja Organisasi dan Proses Bisnis, Jurnal Manajemen Proses Bisnis, Volume 25, Nomor 1, 2019, DOI 10.1108 / BPMJ-02-2019368

[12] Waluyo Adeyaksa Galuh, Ismiarta Aknuranda, Nanang Yudi Setiawan. Analisis Proses Bisnis Pada Toko Buku Galuh Menggunakan Business Process Improvement Framework. Jurnal Pengembangan Teknologi Informasi Dan Ilmu Komputer. Vol. 2. No. 12. Desember 2018. e-ISSN: 2548-964X

[13] Wardhana Bhaswara Aditya, Darminto Pujotomo, Susatyo Nugroho W.P. Usulan Perbaikan Proses Bisnis Dengan Konsep Business Process Reengineering (Studi Kasus : Permata Guest House). J@Ti Undip. Vol Viii, No 1. Januari 2013

[14] Wil Van Der Aalst. Spreadsheets For Business Process Management. Business Process Management Journal. Vol. 24 No. 1, 2018. DOI 10.1108/BPMJ-10-2016-0190 